\title{
Comparison of risk and protective factors for preterm birth in rural, suburban, and urban Fresno County, California
}

\author{
Rebecca J. Baer*1,2, Lauren Lessard³ ${ }^{3}$, Marta Jankowska²,4, James G. Anderson²,5, Jessica Block ${ }^{4}$, Christina D. \\ Chambers $^{1}$, Jonathan Fuchs ${ }^{2,6}$, Miriam Kuppermann ${ }^{2,7,8}$, Monica R. McLemore ${ }^{2,9}$, Gail Newel ${ }^{2,7,10}$, Scott P. Oltman ${ }^{2,7}$, \\ Elizabeth E. Rogers ${ }^{2,5}$, Kelli K. Ryckman ${ }^{11}$, Martina A. Steurer ${ }^{2,5,7}$, Jiue-An Yang ${ }^{4}$, Linda S. Franck ${ }^{2,9}$, Larry Rand La $^{2,8}$ \\ Laura L. Jelliffe-Pawlowski ${ }^{2,7}$ \\ ${ }^{1}$ Department of Pediatrics, University of California San Diego, La Jolla, California, USA \\ ${ }^{2}$ California Preterm Birth Initiative, University of California San Francisco, San Francisco, California, USA \\ ${ }^{3}$ Central Valley Health Policy Institute, California State University Fresno, Fresno, California, USA \\ ${ }^{4}$ Calit2/Qualcomm Institute, University of California San Diego, La Jolla, California, USA \\ ${ }^{5}$ Department of Pediatrics, University of California San Francisco, San Francisco, California, USA \\ ${ }^{6}$ San Francisco Department of Public Health, San Francisco, California, USA \\ ${ }^{7}$ Department of Epidemiology and Biostatistics, University of California San Francisco, San Francisco, California, USA \\ ${ }^{8}$ Department of Obstetrics, Gynecology, and Reproductive Sciences, University of California San Francisco, San Francisco, \\ California, USA \\ ${ }^{9}$ Department of Family Health Care Nursing, School of Nursing, University of California San Francisco, San Francisco, California, \\ USA \\ ${ }^{10}$ Department of Obstetrics and Gynecology, University of California San Francisco Fresno Center for Medical Education and \\ Research, Fresno, California, USA \\ ${ }^{11}$ Departments of Epidemiology and Pediatrics, University of lowa College of Public Health and Carver College of Medicine, lowa \\ City, lowa, USA
}

Received: June 13, 2018

DOI: $10.5430 /$ jer.v4n2p50
Accepted: July 22, 2018

Online Published: August 1, 2018

\begin{abstract}
Preterm birth (PTB, <37 weeks' gestation) may impose lifelong sequelae or death. Fresno County reports the highest rate of PTB in California. A place-based approach investigating local risk factors for PTB may provide important opportunities for intervention and prevention. In this study, we examine risk and protective factors for PTB in rural, suburban, and urban Fresno County, California. The sample was drawn from Fresno County, California singleton births 2007-2012 ( $\mathrm{n}=81,021)$. Multivariate models of maternal risk and protective factors for PTB were stratified by rural, suburban, and urban residence. Women with diabetes, hypertension, infection, fewer than three prenatal care visits, previous PTB, interpregnancy interval less than six months, or were of Black race/ethnicity were at increased risk of PTB. The risk of PTB was highest for women residing in rural locations with preeclampsia superimposed on preexisting hypertension (adjusted relative risk (aRR) $5.7,95 \%$ confidence interval (CI) 4.4-7.4). For women living in urban residences, maternal birth in Mexico and overweight body mass index (BMI) offered protection from PTB (aRRs 0.9), whereas participation in the Women, Infants and Children program was protective for women in either urban or rural residences (aRRs 0.8). Public insurance, $<12$ year of education, underweight BMI, and
\end{abstract}

\footnotetext{
*Correspondence: Rebecca J. Baer, MPH; Email: rjbaer@ucsd.edu; Address: Department of Pediatrics, University of California San Diego, La Jolla, California, USA.
} 
interpregnancy interval of five years or more were risk factors only for women in urban residences. These findings may provide important opportunities for local intervention.

Key Words: Preterm birth, Risk factor, Place-based, Fresno County, California, Protective factor

\section{INTRODUCTION}

Health complications related to preterm birth (prior to 37 weeks' gestation) may impose lifelong sequelae or death. ${ }^{[1,2]}$ In the United States, $17 \%$ to $34 \%$ of infant deaths within the first year of life are attributable to prematurity. ${ }^{[3]}$ Children born preterm are more likely to have vision or hearing loss, cerebral palsy, and physical or learning delays. ${ }^{[4]}$ The societal economic burden associated with preterm birth in the United States was estimated to be over $\$ 26$ billion annually more than a decade ago. ${ }^{[3]}$

Years of study have identified numerous risk factors for preterm birth, including obesity, hypertension, diabetes, smoking, drug or alcohol dependence/abuse during pregnancy and a short interval between pregnancies. ${ }^{[5-8]}$ Few protective factors against preterm birth have been identified, but include maternal birth outside of the United States and interpregnancy interval of 24 to 60 months. ${ }^{[5]}$ Identification of risk and protective factors has not decreased preterm birth rates in the United States - instead rates have been showing an upward trend. ${ }^{[9]}$

In an effort to improve infant health outcomes, there has been a recent upsurge in efforts to reduce preterm birth rates in the United States. ${ }^{[10-12]}$ This effort is challenging, due to the complex biology of preterm birth, various clinical presentations, and socioeconomic and psychosocial influences. ${ }^{[1,13-17]}$ Due to the need for multipronged approaches to decrease preterm birth rates, a collaborative place-based approach may be an effective way to decrease rates locally. A place-based approach is designed to take into account the unique local and contextual conditions of specific locations, engage a diverse range of sectors in a collaborative decisionmaking process, and leverage local talent, knowledge, and assets. ${ }^{[18]}$ By addressing drivers of preterm birth that may be more frequent based on location (e.g. high rates of smoking), this method recognizes that one size may not fit all, either in terms of drivers or interventions.

California reports a 2016 preterm birth rate of $8.5 \%$, with the highest rate in Fresno County, located in the Central Valley region. ${ }^{[19]}$ Fresno County has just under one million residents, half of whom are Hispanic, and has the highest value of agricultural crops by any county in the United States. ${ }^{[20,21]}$ Fresno County reports the highest poverty rate in California, with $32.3 \%$ of families with children living below the

Published by Sciedu Press poverty level, and is considered a Primary Care Health Professional Shortage Area. ${ }^{[20-22]}$ In this study we evaluated the influences of maternal characteristics and obstetric factors on timing of birth in Fresno County to evaluate both risk and prevalence of risk by urban, suburban, and rural residence. We aimed to identify risk and protective factors for birth before 37 weeks' gestation that can inform policy and health care priorities designed to reduce preterm birth rates in Fresno County.

\section{Methods}

In this retrospective cohort study, our sample was drawn from California live births between January 1, 2007 and December 31,2012. The sample was restricted to women with singleton births with best obstetric estimate of gestation at delivery between 20 and 44 weeks, linked to the birth cohort database maintained by the California Office of Statewide Health Planning and Development, with no known chromosomal abnormalities or major structural birth defects, and a Fresno County census tract (see Supplemental Figure 1). The birth cohort database contained linked birth and death certificates, as well as detailed information on maternal and infant characteristics, hospital discharge diagnoses and procedures recorded as early as one year before delivery and as late as one year post-delivery. Data files provided diagnoses and procedure codes based on the International Classification of Diseases, 9th Revision, Clinical Modification (ICD-9). ${ }^{[23]}$ Structural birth defects for the study were considered "major" if determined by clinical review as causing major morbidity and mortality that would likely be identified in the hospital at birth or lead to hospitalization during the first year of life. ${ }^{[24]}$

The sample of Fresno County women was stratified by residence in urban, suburban and rural census tracts as defined by the Medical Service Study Areas (MSSAs) (see Table 1). MSSAs "are recognized by the U.S. Health Resources and Services Administration, Bureau of Health Professions' Office of Shortage Designation as rational service areas for purposes of designating Health Professional Shortage Areas (HPSAs), and Medically Underserved Areas and Medically Underserved Populations (MUAs/MUPs)". [22]

Within each of these residence strata, known maternal preterm birth risk factors were compared for women who delivered before 37 weeks' gestation to those of women who 
delivered between 37 and 44 completed weeks' gestation, using Poisson logistic regression to calculate crude relative risks (RR) and 95\% confidence intervals (95\% CI). Comparisons using data from birth certificate records included race/ethnicity, maternal age, education, payment for delivery, participation in the Women, Infants, and Children program (WIC, a federally-funded health and nutrition program for women who are pregnant, new mothers, or with children under five, and meet specified income guidelines), ${ }^{[25]}$ parity, maternal birthplace, report of smoking during pregnancy, maternal body mass index (BMI) (calculated from pre-pregnancy weight and height), trimester when prenatal care began, and number of prenatal care visits.

Table 1. Medical Service Study Areas (MSSA) used for urban, suburban, and rural residence stratification

\begin{tabular}{|c|c|c|}
\hline $\begin{array}{l}\text { Residence } \\
\text { stratification }\end{array}$ & $\begin{array}{l}\text { MSSA } \\
\text { ID }\end{array}$ & MSSA name \\
\hline \multirow{3}{*}{ Urban } & $35 c$ & Fresno West Central \\
\hline & $35 d$ & Fresno East Central \\
\hline & $35 f$ & Fresno North Central \\
\hline \multirow{3}{*}{ Suburban } & $35 a$ & Fresno Northwest \\
\hline & $35 b$ & Clovis West/Fresno East \\
\hline & $35 e$ & Fresno South and West \\
\hline \multirow{10}{*}{ Rural } & 25 & Firebaugh/Mendota \\
\hline & 26 & Cantua Creek/San Joaquin/lianquility \\
\hline & 27 & Coalinga \\
\hline & 28 & Huron \\
\hline & 29 & Biola/Herndon/Highway City/Kerman \\
\hline & 30 & $\begin{array}{l}\text { Bowles/Caruthers/Easton/Kingsburg/Lanare/ } \\
\text { Laton/Raisin City/ Riverdale/Selma }\end{array}$ \\
\hline & 31 & Auberry/Calwa/Centerville/Clovis East/Del \\
\hline & & Rey/Fowler/ Friant/ Sanger/Shaver Lake \\
\hline & 32 & Orange Cove/Parlier/Reedley/Squaw \\
\hline & & Valley/Tivy Valley/Wonder Valley \\
\hline
\end{tabular}

For multiparous women, we examined the relationship between preterm birth and previous preterm birth, previous cesarean delivery, and interpregnancy interval. Interpregnancy interval was calculated from previous live birth (month and year) as reported in linked records and estimated as months to conception of the index pregnancy. Given that the day of previous live birth was not available, the middle of the month was used for calculation purposes. ${ }^{[8]}$

Factors from hospital discharge ICD-9 diagnoses included: Preexisting hypertension without progression to preeclampsia, preexisting hypertension with progression to preeclampsia, gestational hypertension without progression to preeclampsia, gestational hypertension with progression to preeclampsia, preexisting diabetes, and gestational diabetes. We also compared preterm birth with respect to the frequency of coded infection, anemia, drug or alcohol dependence/abuse, and mental disorder (see Table 2).
Multivariable models of maternal risk and protective factors for preterm birth were built for each location of residence category (urban, suburban, rural) using backwards-stepwise Poisson logistic regression wherein initial inclusion was determined by a threshold of $p<.20$ in crude analyses. Adjusted RRs (aRRs) and their 95\% CIs were calculated for each residence stratum. In an effort to visualize overall risk of preterm birth by census tract, cumulative risk scores estimated the overall risk of preterm birth. Scores were calculated for each woman by adding her risks (aRR - 1) and subtracting her protective factors $((1 / \mathrm{aRR})-1)$ remaining in the final multivariable model. Risk scores were grouped into scores 0.0 or less, 0.1 to $0.9,1.0$ to $1.9,2.0$ to 2.9 and 3.0 or more.

Drug dependence/abuse and mental illnesses were further classified based on ICD-9 diagnostic codes, although risks calculations were not computed due to small numbers. Drug dependence/abuse was defined by classification of drug: opioid, cocaine, cannabis, amphetamine, other drug dependence/abuse, and polysubstance dependence/abuse. Mental illnesses were further classified as: schizophrenic disorders, bipolar disorder, major depression, depressive disorder, anxiety disorders, personality disorders, and more than one of the previously mentioned categories. Infection was further classified as asymptomatic bacteriuria, urinary tract infection, sexually transmitted infection, and viral infection (see Table 2).

Additionally, rates of preterm birth by subgroup (both by gestational age group and classification, i.e., spontaneous or provider-initiated) were examined. As previously described, ${ }^{[15]}$ pregnancies resulting in spontaneous preterm birth were considered to be those where birth certificate or hospital discharge records indicated premature rupture of membranes (PROM), premature labor, or those for whom tocolytic medications were administered. Pregnancies resulting in provider initiated preterm births were considered to be those without PROM, premature labor or tocolytic administration for which there was a code for "induction" or "artificial rupture of membranes"; or for which there was a cesarean delivery without any of the aforementioned codes. Counts and rates were not reported when $\mathrm{n}<16$ to protect the identity of individuals in the dataset.

All analyses were performed using Statistical Analysis Software version 9.4 (Cary, NC). Methods and protocols for the study were approved by the Committee for the Protection of Human Subjects within the Health and Human Services Agency of the State of California. Data used for the study were received by the California Preterm Birth Initiative (PTBi-CA) at the University of California San Francisco by June 2016. 
Table 2. Diagnostic codes used from hospital discharge records

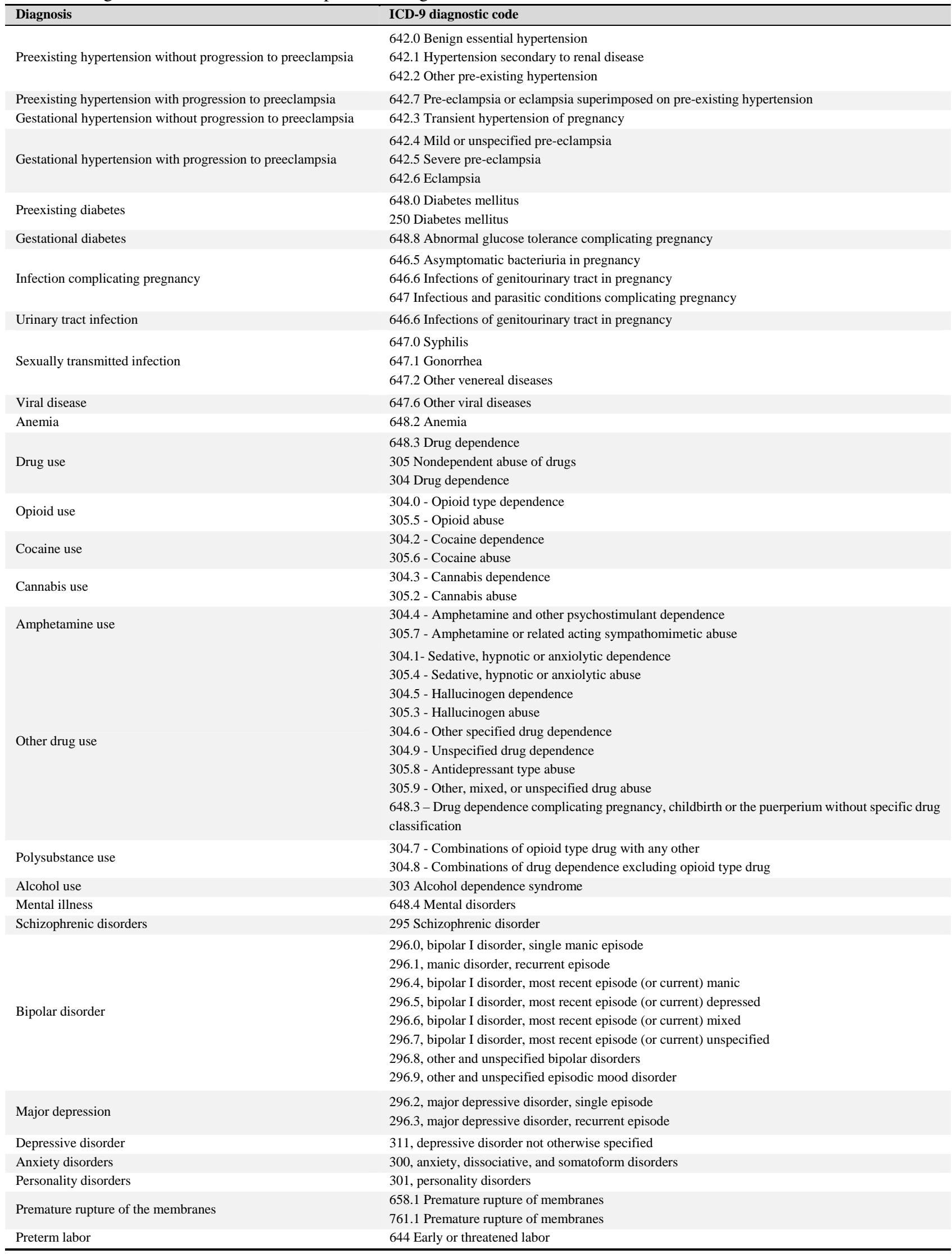




\section{RESUltS}

The sample included 81,021 women: 29,052 (35.9\%) with urban residence, 24,377 (28.9\%) with suburban residence and 27,592 (34.1\%) with rural residence. The majority of the women in the sample were Hispanic (60.3\%), between 18 and 34 years at delivery (84.4\%), WIC participants (72.0\%), and multiparous $(65.5 \%)$. Thirty-five percent of the women in this sample were born outside of the United States. The demographic makeup of the three residence locations differed. For example, $8.0 \%$ of the urban population, $6.7 \%$ of suburban mothers, and $2.2 \%$ of the rural population was Black race/ethnicity (see Table 3).

Table 3. Sample characteristics by urban, suburban, or rural maternal residence: Fresno County singleton births, 2007 to $2012, \mathrm{n}=81,021$

\begin{tabular}{|c|c|c|c|}
\hline & Urban $(n=29,052)$ & Suburban $(n=24,377)$ & Rural $(27,592)$ \\
\hline Characteristic & n (\%) & n (\%) & n (\%) \\
\hline \multicolumn{4}{|l|}{ Race or Ethnicity } \\
\hline White not Hispanic & 4,623 (15.9) & $6,823(28.0)$ & 3,972 (14.4) \\
\hline Hispanic & $17,014(58.6)$ & $11,360(46.6)$ & $20,486(74.3)$ \\
\hline Black & 2,319 (8.0) & $1,642(6.7)$ & $599(2.2)$ \\
\hline Asian & 3,621 (12.5) & 3,261 (13.4) & $1,257(4.6)$ \\
\hline Other $^{\mathrm{a}}$ & $1,475(5.1)$ & $1,291(5.3)$ & $1,278(4.6)$ \\
\hline \multicolumn{4}{|l|}{ Parity } \\
\hline Nulliparous & 9,818 (33.8) & 8,833 (36.2) & 8,861 (32.1) \\
\hline Multiparous & $19,078(65.7)$ & $15,357(63.0)$ & $18,632(67.5)$ \\
\hline \multicolumn{4}{|l|}{ Maternal Age } \\
\hline Less than 18 years & $1,470(5.1)$ & $942(3.9)$ & $1,308(4.7)$ \\
\hline 18 to 34 years & $24,888(85.7)$ & $20,482(84.0)$ & 22,991 (83.3) \\
\hline More than 34 years & 2,693 (9.3) & 2,953 (12.1) & 3,290 (11.9) \\
\hline \multicolumn{4}{|l|}{ Education } \\
\hline Less than 12 years & $10,153(35.0)$ & $5,561(22.8)$ & $10,162(36.8)$ \\
\hline 12 years & 8,586 (29.6) & 6,495 (26.6) & $7,662(27.8)$ \\
\hline More than 12 years & 9,218 (31.7) & $11,226(46.1)$ & 8,877 (32.2) \\
\hline \multicolumn{4}{|l|}{ Payment for delivery } \\
\hline Private insurance & 5,592 (19.3) & $9,440(38.7)$ & 6,141 (22.3) \\
\hline Medi-Cal $^{\mathrm{b}}$ & 22,977 (79.1) & 14,612 (59.9) & $20,821(75.5)$ \\
\hline Other $^{c}$ & $483(1.7)$ & $325(1.3)$ & $630(2.3)$ \\
\hline Participant in WIC ${ }^{\mathrm{d}}$ & 22,495 (77.4) & 14,353 (58.9) & $21,487(77.8)$ \\
\hline \multicolumn{4}{|l|}{ Location of mother's birth } \\
\hline U.S. & $19,975(68.8)$ & $17,458(71.6)$ & $15,054(55.2)$ \\
\hline Mexico & $6,465(22.3)$ & $3,942(16.2)$ & $10,553(38.3)$ \\
\hline Other country (not Mexico) & $2,612(9.0)$ & 2,977 (12.2) & $1,814(6.6)$ \\
\hline
\end{tabular}

ancludes: American Indian, Hawaiian or Pacific Islander, Other race, Two or more races and Unknown race or ethnicity

${ }^{\mathrm{b} C a l i f o r n i a}$ 's Medicaid

'Includes: no pay, other government pay, other pay, self-pay, unknown pay

${ }^{\mathrm{d}}$ Women, Infants and Children Program

Nine percent of women in urban residences, $8.0 \%$ of women in suburban residences, and $8.2 \%$ of women in rural residences delivered preterm (see Figure 1, Supplemental Table 1, Supplemental Table 2). Of these, $1.4 \%$ of women living in urban residences delivered before 32 weeks, while $1.1 \%$ of women in suburban or rural residences delivered this early. More specifically, $1.7 \%$ of women in the Fresno East Central MSSA delivered before 32 weeks (see Supplemental Table 2). Four individual census tracts within urban MSSAs had rates of birth at less than 32 weeks' gestation of $2.0 \%$ or greater, with an $\mathrm{n}$ of 16 or more as the reporting threshold (see Supplemental Table 7).

In the final multivariable logistic models, Black women were found to be at elevated risk of preterm birth across all residence strata (urban aRR 1.2, 95\% CI 1.1 to 1.4 ; suburban aRR $1.4,95 \%$ CI 1.2 to 1.6 ; rural aRR $1.4,95 \%$ IC 1.1 to 1.8). Similarly, women with interpregnancy intervals less than six months were at elevated risk across residence strata (urban aRR 1.5, 95\% CI 1.3 to 1.7; suburban aRR 1.4, 95\% 
CI 1.2 to 1.7 ; rural aRR $1.4,95 \%$ IC 1.1 to 1.7$)$. Women with comorbidities such as preexisting and gestational diabetes, preexisting hypertension, and infection were also at increased risk of having a preterm birth. Other factors, such as public insurance (Medi-Cal, California's Medicaid, health insurance coverage for low income persons) for delivery, less than 12 years of education, underweight BMI, and an interpregnancy interval over 59 months, were only risk factors for women living in urban residences. Only Hispanic women in rural residences were at increased risk of preterm birth (aRR $1.1,95 \%$ CI 1.0 to $1.3, p<.05)$. Women living in urban and rural residences who participated in WIC were less likely to deliver preterm (aRR $0.8,95 \%$ CI 0.7 to 0.9 , and aRR $0.9,95 \%$ CI 0.8 to $1.0, p=.017$, respectively). For urban women, birth in Mexico and overweight BMI also showed a protective effect to preterm birth (Figure 2).

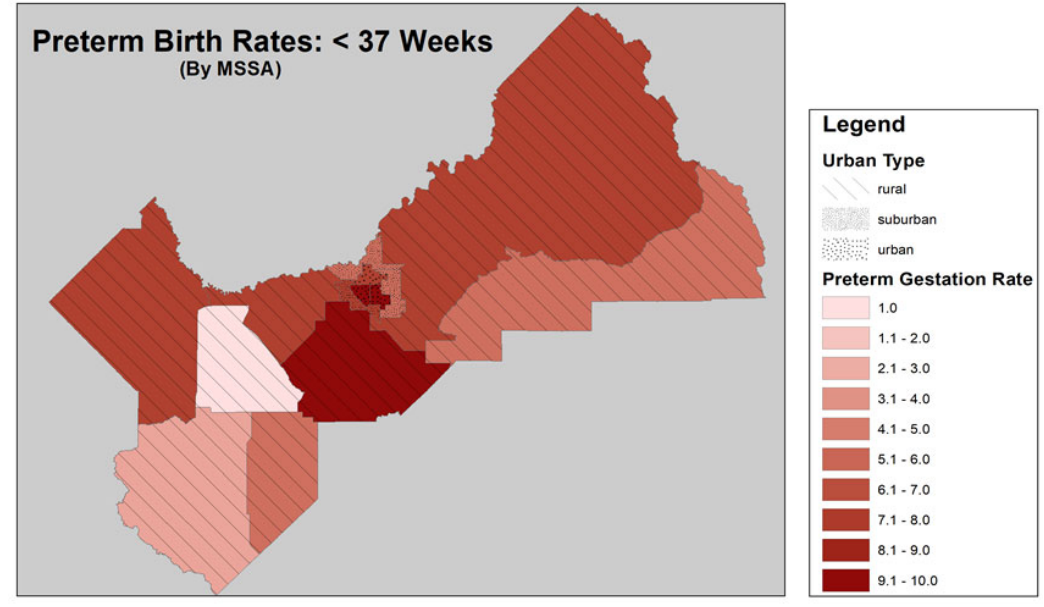

Figure 1. Preterm birth rates by urban, suburban, and rural Fresno County, California, singleton births, 2007 to 2012 , $\mathrm{n}=$ 81,021

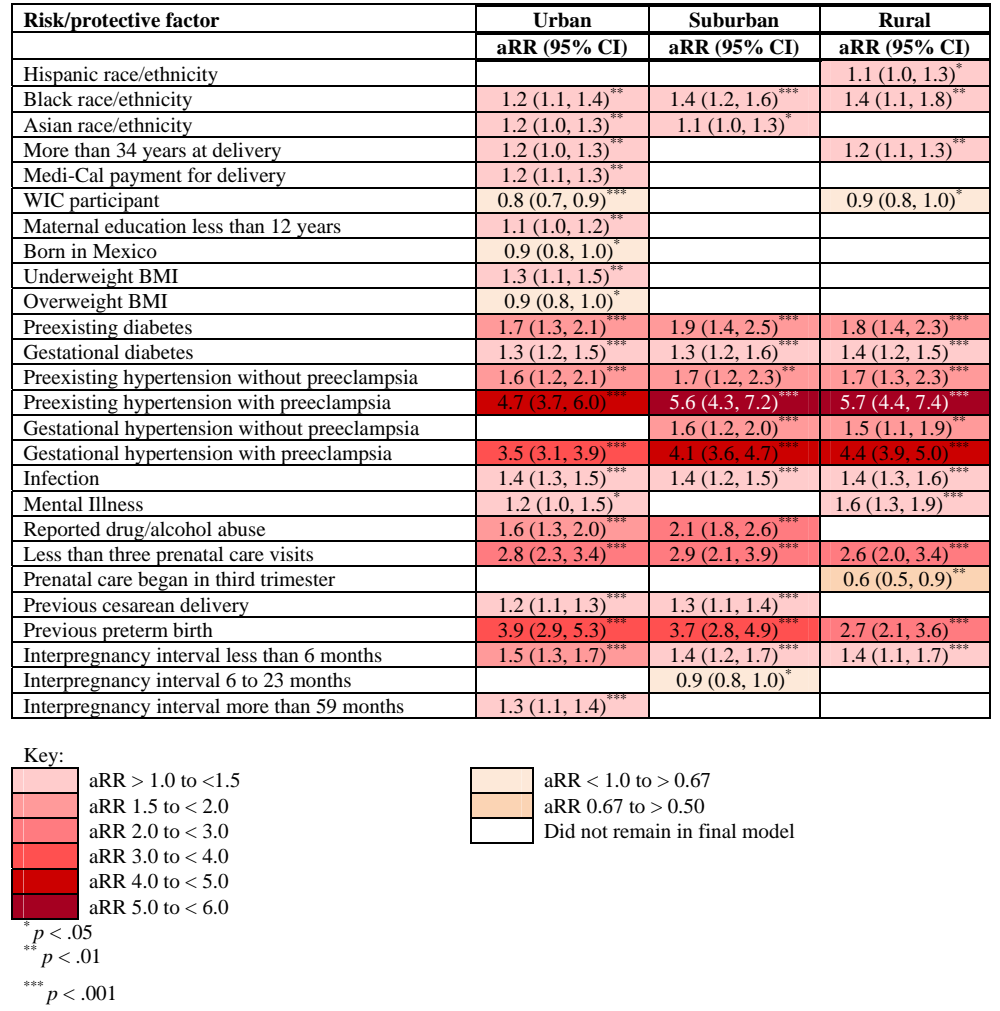

Figure 2. Heatmap of maternal characteristics and obstetric factors in preterm birth final multivariate logistic model by urban, suburban, or rural maternal residence, Fresno County singleton births, 2007 to 2012 
Not only did the risk models differ by residence within Fresno County, but the percentage of women with the risk varied greatly for some factors. In urban residences, $12.2 \%$ of women with preterm births smoked, while $6.6 \%$ of women in rural residences with preterm birth smoked. Similarly, $8.9 \%$ of urban women with a preterm birth used drugs or alcohol and $4.4 \%$ women in rural residences with preterm birth did. Nearly five percent of urban women delivering preterm had fewer than three prenatal care visits and $2.3 \%$ of women in suburban residences had this few number of visits. The percent of women with a preterm birth and with interpregnancy intervals less than six months ranged from $7.7 \%$ (rural) to $11.2 \%$ (urban) (see Supplemental Table 1).
When examining these risk factors in more geographic detail, appropriate targets for preterm birth reduction are elucidated. For instance, in six census tracts $15 \%$ or more mothers of preterm infants smoked during their pregnancy - four in urban residences and two in suburban residences (see Supplemental Tables 12, 13 and 14). Also, five census tracts in urban residences show that over $10 \%$ of mothers who delivered preterm used drugs or alcohol (see Supplemental Table 12).

Over 2,600 women delivering in Fresno County had a cumulative risk score for preterm birth $\geq 3.0: 2.2 \%$ of women living in urban residences, $4.1 \%$ in suburban, and $3.7 \%$ in rural residences had this high risk score (see Figure 3).

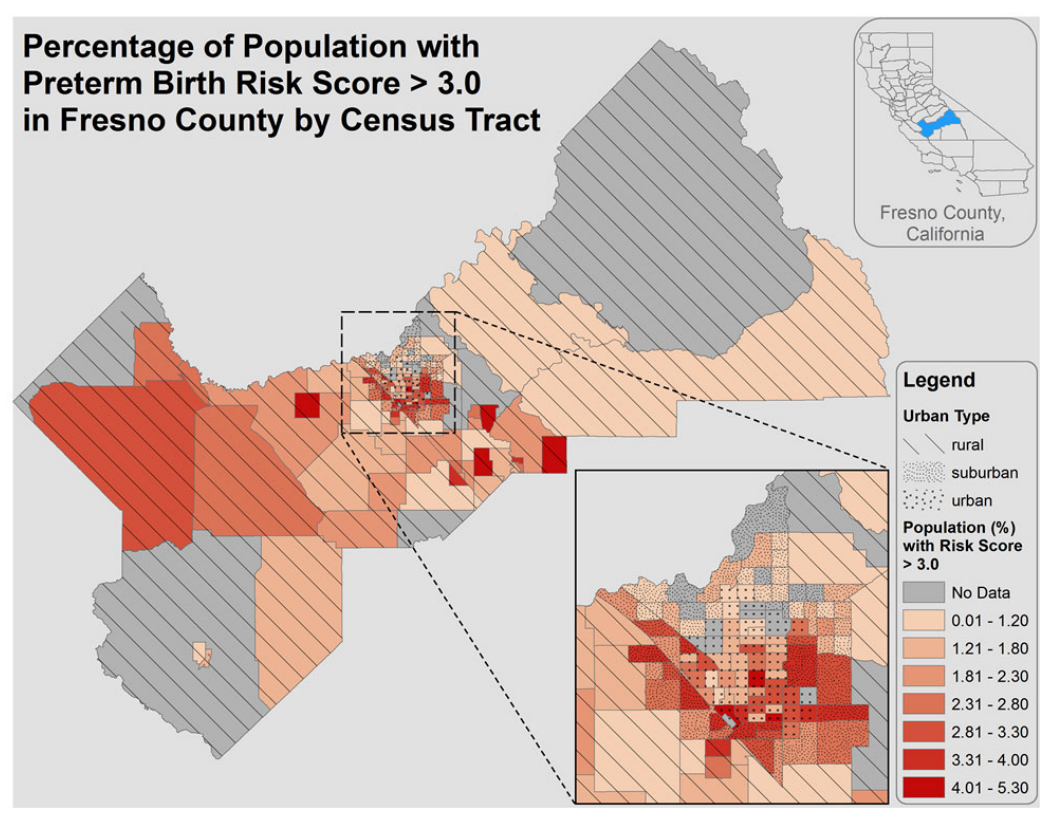

Figure 3. Percent of population with risk score $>3$.0, Fresno County singleton births, 2007 to 2012

\section{Discussion}

In this study of preterm births in Fresno County, we found that differences in the type and magnitude of risk and protective factors differed by the residence (urban, suburban, and rural) in which women reside. Black women and women with diabetes, hypertension, infection, fewer than three prenatal care visits, previous preterm birth or interpregnancy interval less than six months were at increased risk of preterm birth, regardless of location of residence. Public insurance, maternal education less than 12 years, underweight BMI, and interpregnancy interval of five years or more were identified as risk factors only for women in urban residences. Women living in urban locations who were born in Mexico and who were overweight by BMI were at lower risk for preterm birth; WIC participation was protective for women in both urban and rural locations. Taken together, these findings suggest tar- geted place-based interventions and policy recommendations can be pursued.

The preterm birth risk factors identified in these analyses are not unique to Fresno County: previous work has also shown that women of color, lower education, lower socioeconomic status, women with co-morbidities such as hypertension and diabetes, smoking, and short interpregnancy interval are at elevated risk of preterm birth. ${ }^{[5,26,27]}$ In Fresno County, however, we observed that these risks differ in magnitude. This is critical, as the percentage of women in each region with the risk factor can vary greatly. Hispanic women were at increased risk of preterm birth in rural residence. The degree of risk was mild - only a 1.1-fold increase in risk. However, $72 \%$ of the population giving birth in rural Fresno County is Hispanic, suggesting that focusing interventions reaching this population may provide the most impact. Similarly, 
Black women were at elevated risk of preterm birth regardless of location of residence. Since urban residences have the highest percentage of Black women (8.0\%) and rural has the lowest (2.2\%), focusing prevention efforts for Black women in urban residences may be an effective approach.

Others have found that with pre-pregnancy initiation of Medicaid (low-income health insurance), has been associated with earlier initiation of prenatal care, ${ }^{[28]}$ a factor that may reduce preterm birth rates. ${ }^{[29]}$ In addition, participation in the WIC program also has shown a moderate reduction of the risk of a small for gestational age infant ${ }^{[30]}$ and has been associated with reduced infant mortality in Black populations. ${ }^{[31]}$ Fresno women from both urban and rural residences who participated in the WIC program were less likely to deliver preterm, while those women living in urban locations who were publicly insured through Medi-Cal coverage for delivery were at increased risk for preterm birth. Low income is a criterion for both public assistance programs, and over 32\% of families in this region lives below the poverty line; ${ }^{[22]}$ it is apparent that social economic status is a complex risk factor for preterm birth. A key take away message from this study is that women who accessed prenatal care more frequently three or more prenatal care visits - were less likely to deliver preterm. Fresno County may be able to improve preterm birth rates by addressing factors that encourage prenatal care access, which may include enrollment in Medi-Cal during the preconception period and increasing WIC participation. Identifying regions where a high percentage of women do not access three or more prenatal care visits may suggest locations for an intervention such as home visits or mobile clinic.

Using a large administrative database allows for examination of rates and risks that would not be possible with other data sources. Despite these strengths, the study has some critical limitations. By design, the findings are very specific to one area of California and may not be as applicable to other areas of the state, country, or world. In fact, we recently conducted a similar study examining preterm birth risk factors by subtype for all of California. ${ }^{[5]}$ Our findings in Fresno County identified both similar and different risk factors for preterm birth. Similar to the entire California population, we demonstrated increased risk of preterm birth for Fresno County women who were of Black race/ethnicity, who had diabetes or hypertension during pregnancy, or who had a previous preterm birth. However, Fresno County was different from the whole state in a few ways. Unlike the state of California as a whole, Hispanic women, women over 34 years at delivery, and underweight women in urban residences in Fresno County were at increased risk for preterm birth. Also, education over 12 years did not provide protection against

Published by Sciedu Press preterm birth in any of the Fresno County residences, although higher education did provide protection when we looked at the whole state of California. These differences point to specific pathways occurring in Fresno County that may be distinct from the state as a whole, and demonstrate the value of place-based investigation of risk factors when examining a complex outcome such as preterm birth. Other residences may benefit from similar analyses to identify risk and protective factors that are important on a local level.

An additional limitation, as with most administrative databases, is that accuracy and ascertainment of variables is not easily validated. Previous studies of California birth certificate data suggests that race/ethnicity is a valid measure of self-identified race/ethnicity for all but Native Americans, and best obstetric estimate of gestation may underestimate preterm delivery rates. ${ }^{[32,33]}$ Previously reported rates of preterm birth in Fresno County are around $9.5 \%$ and was $8.4 \%$ overall in our population after removing multiple gestation pregnancies and pregnancies with major birth defects. Additionally, United States estimates for drug dependence/use during pregnancy is $5.0 \%$ to $5.4 \%{ }^{[5]}$ and was only $2.5 \%$ in our population. This under ascertainment may mean that we are capturing the most severe diagnoses, potentially overestimating our risk calculations. Alternatively, under ascertainment also implies that drug users were likely in our referent population, which would underestimate our risk calculations.

This examination of Fresno County preterm birth may provide important opportunities for local intervention. Several populations were identified as at risk, regardless of location of maternal residence, that deserve targeted interventions. Interventions focused on diabetes, hypertension, and drug or alcohol dependence/abuse across the county may be effective for preterm birth reduction.

We identified several modifiable risk and resilience factors across the reproductive life course that can be addressed to reduce preterm birth rates. Given the complex clinical and social determinants that influence preterm birth, cross-sector collaborative efforts that take into account place-based contextual factors may be helpful and are actively being pursued in Fresno County. Ultimately, refining our understanding of risk and resilience and how these factors vary across a geography are fundamental steps in pursuing a precision public health approach to achieve health equity.

Note: The Supplemental figure and tables can be obtained from the authors and the editor.

\section{CONFLicts OF INTEREST Disclosure}

The authors of this article declare that they have no conflicts of interest. 


\section{REFERENCES}

[1] Goldenberg RL, Culhane JF, Iams JD, et al. Epidemiology and causes of preterm birth. Lancet. 2008; 371(9606): 75-84. PMid: 18177778 https ://doi.org/10.1016/s0140-6736(08)60074-4

[2] Stoll BJ, Hansen NI, Bell EF, et al. Neonatal outcomes of extremely preterm infants from the NICHD Neonatal Research Network. Pediatrics. 2010; 126(3): 443-56. PMid: 20732945. https : //doi.org/10.1542/peds. 2009-2959.

[3] Committee on Understanding Premature Birth and Assuring Healthy Outcomes BoHSP. Preterm Birth: Causes, Consequences, and Prevention. 2007.

[4] Saigal S, Doyle LW. An overview of mortality and sequelae of preterm birth from infancy to adulthood. Lancet. 2008; 371(9608): 261-9. PMid: 18207020. https://doi.org/10.1016/s0140-6 736 (08)60136-1.

[5] Jelliffe-Pawlowski LL, Baer RJ, Blumenfeld YJ, et al. Maternal characteristics and mid-pregnancy serum biomarkers as risk factors for subtypes of preterm birth. BJOG. 2015. PMid: 26111589. https://doi.org/10.1111/1471-0528.13495

[6] Baer RJ, Chambers CD, Ryckman KK, et al. Risk of preterm birth among women using drugs during pregnancy with elevated alphafetoprotein. J Perinatol. 2016. PMid: 27929528. https://doi.or g/10.1038/jp. 2016.224

[7] Cnattingius S, Villamor E, Johansson S, et al. Maternal obesity and risk of preterm delivery. JAMA. 2013; 309(22): 2362-70. PMid: 23757084. https://doi.org/10.1001/jama.2013.6295

[8] Shachar BZ, Mayo JA, Lyell DJ, et al. Interpregnancy interval after live birth or pregnancy termination and estimated risk of preterm birth: a retrospective cohort study. Bjog. 2016. PMid: 27405702. https://doi.org/10.1111/1471-0528.14165

[9] Hamilton BEM JA, Osterman MJK, Driscoll AK, et al. Births: Provisional Data for 2016. Natl Vital Stat Rep. 2017; 12(64): 1-64.

[10] March of Dimes [Internet]. Aug 2017 [cited 2017 Aug 17]. Available from: http: //www.marchofdimes .org/

[11] Healthy People 2020 [Internet]. Aug 2017 [cited 2017 Aug 17]. Available from: https://www.healthypeople.gov/2020/top ics-objectives/topic/maternal-infant-and-child-hea 1th/objectives

[12] UCSF Preterm Birth Initiative [Internet]. Aug 2017 [cited 2017 Aug 17]. Available from: http://pretermbirth.ucsf.edu/

[13] Romero R, Dey SK, Fisher SJ. Preterm labor: one syndrome, many causes. Science. 2014; 345(6198): 760-5. PMid: 25124429. https://doi.org/10.1126/science.1251816

[14] Romero R, Espinoza J, Kusanovic JP, et al. The preterm parturition syndrome. BJOG. 2006; 113 Suppl 3: 17-42. PMid: 17206962 https://doi.org/10.1111/j.1471-0528.2006.01120.x

[15] Henderson JJ, McWilliam OA, Newnham JP, et al. Preterm birth aetiology 2004-2008. Maternal factors associated with three phenotypes: spontaneous preterm labour, preterm pre-labour rupture of membranes and medically indicated preterm birth. J Matern Fetal Neonatal Med. 2012; 25(6): 642-7. PMid: 21827362. https: //doi.org/10.3109/14767058.2011.597899.

[16] Barros FC, Papageorghiou AT, Victora CG, et al. The distribution of clinical phenotypes of preterm birth syndrome: implications for prevention. JAMA Pediatr. 2015; 169(3): 220-9. PMid: 25561016. https://doi.org/10.1001/jamapediatrics.2014.3040

[17] Muglia LJ, Katz M. The enigma of spontaneous preterm birth. N Engl J Med. 2010; 362(6): 529-35. PMid: 20147718. https: //doi.org/10.1056/NEJMra0904308

[18] Canada PH. The Evaluation of Place-Based Approaches 2011 [Internet]. Jun 2017 Aug 2017 [cited 2017 Jun 12]. Available from:
http://www.horizons.gc.ca/sites/default/files/Pub lication-alt-format/2011_0074_evaluationpb_e.pdf

[19] March of Dimes. Premature Birth Report Card 2015 [Internet]. Jun 2015 [cited 2015 Jun 15]. Available from: http://www .marchofdimes.org/materials/premature -birth-report-card-california.pdf

[20] United States Census Bureau [Internet]. Aug 2010 [cited 2017 Aug 17]. Available from: https://www.census.gov/quickfacts/ fact/table/fresnocountycalifornia/PST045216

[21] Fresno County Governments. Fresno County at a Glance 2011 [Internet] Jul 2017 [cited 2017 Jul 26]. Available from: http://www.fresnocog.org/sites/default/files/publ ications/One_Voice_Sacramento/Fresno_County_at_a_g lance_2012_8-5X11.pdf

[22] Office of of Statewide Health Planning and Development [Internet]. Jul 2015 [cited 2015 Jul 14]. Available from: http: //www . oshpd. ca.gov/hwdd/mssa/maps/Fresnopc.pdf

[23] American Medical Association. International Classification of Diseases: ICD-9-CM 2008. 2008 ed. Chicago, IL: American Medical Association; 2007.

[24] Baer RJ, Norton ME, Shaw GM, et al. Risk of selected structural abnormalities in infants after increased nuchal translucency measurement. Am J Obstet Gynecol. 2014; 211(6): 675 e1-19. PMid: 24949541. https://doi.org/10.1016/j.ajog. 2014.06.025

[25] United States Department of Agriculture [Internet]. Aug 2017 [cited 2017 Aug 17]. Available from: https://www.fns.usda.gov/w ic/women-infants-and-children-wic

[26] Catov JM, Nohr EA, Olsen J, et al. Chronic hypertension related to risk for preterm and term small for gestational age births. Obstet Gynecol. 2008; 112(2 Pt 1): 290-6. PMid: 18669725. https : //doi.org/10.1097/AOG.0b013e31817f589b

[27] Sibai BM, Caritis SN, Hauth JC, et al. Preterm delivery in women with pregestational diabetes mellitus or chronic hypertension relative to women with uncomplicated pregnancies. The National institute of Child health and Human Development Maternal-Fetal Medicine Units Network. Am J Obstet Gynecol. 2000; 183(6): 1520-4. PMid: 11120521.

[28] Rosenberg D, Handler A, Rankin KM, et al. Prenatal care initiation among very low-income women in the aftermath of welfare reform: does pre-pregnancy Medicaid coverage make a difference? Matern Child Health J. 2007; 11(1): 11-7. PMid: 16763773. https://doi.org/10.1007/s10995-006-0077-z

[29] Vintzileos AM, Ananth CV, Smulian JC, et al. The impact of prenatal care in the United States on preterm births in the presence and absence of antenatal high-risk conditions. Am J Obstet Gynecol. 2002; 187(5): 1254-7.

[30] Gueorguieva R, Morse SB, Roth J. Length of prenatal participation in WIC and risk of delivering a small for gestational age infant: Florida, 1996-2004. Matern Child Health J. 2009; 13(4): 479-88. PMid: 18661219. https ://doi.org/10.1007/s10995-008-0391-8

[31] Khanani I, Elam J, Hearn R, et al. The impact of prenatal WIC participation on infant mortality and racial disparities. Am J Public Health. 2010; 100 Suppl 1: S204-9. PMid: 20147683. https: //doi.org/10.2105/ajph.2009.168922

[32] Baumeister L, Marchi K, Pearl M, et al. The validity of information on "race" and "Hispanic ethnicity" in California birth certificate data. Health Serv Res. 2000; 35(4): 869-83. PMid: 11055453.

[33] Barradas DT, Dietz PM, Pearl M, et al. Validation of obstetric estimate using early ultrasound: 2007 California birth certificates. Paediatr Perinat Epidemiol. 2014; 28(1): 3-10. PMid: 24117928. https://doi.org/10.1111/ppe.12083 